\title{
Correspondence
}

\section{Massive extension of the suprapatellar pouch into the thigh tissues in rheumatoid disease}

SIR, A 74 year old woman presented to the outpatient department for routine review. She had had seropositive rheumatoid arthritis for two years and despite aggressive therapy with prednisolone and chlorambucil the disease was not yet under control. On this occasion she had active disease in most joints but particularly the knees. She had morning stiffness for three hours and her erythrocyte sedimentation rate was $54 \mathrm{~mm} / 1 \mathrm{st} \mathrm{h}$.

On further examination a cystic swelling measuring 20 $\mathrm{cm} \times 5 \mathrm{~cm}$ was observed lying longitudinally in the deep tissues of the right thigh. A test for fluctuation hinted at a likely connection with the knee joint (Fig. 1).

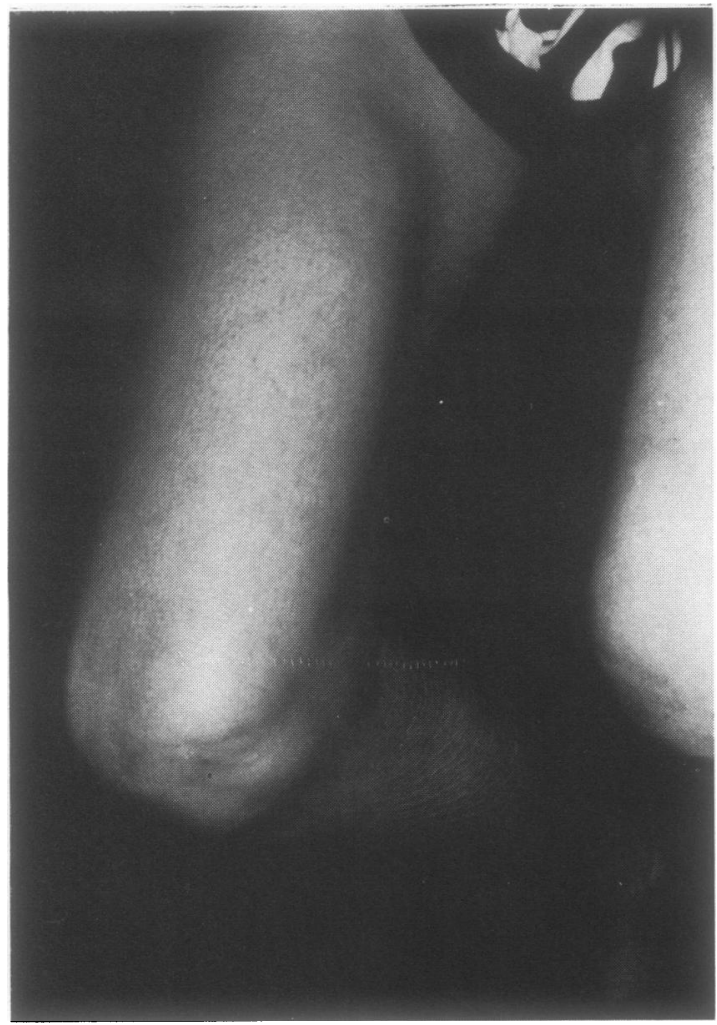

Fig. 1 A large cystic swelling of the right thigh extending almost to the groin.
Fig. 2 Arthrogram of the right knee: lateral view. Note the large multiloculated cyst arising from the suprapatellar pouch and extending into the thigh. A small popliteal cyst, $\mathrm{N}$ which gave rise to symptoms one year ago, remains visible.

Arthrography confirmed that this cystic structure was $a$ large multilocated extension of the suprapatellar poucke (Fig. 2). Aspiration showed a caseous yellow debris, which $\bar{\emptyset}$ was removed by lavage.

\section{Discussion}

Popliteal cysts, often connected to the knee joint by 
valvular mechanism, are well documented in rheumatoid arthritis. ${ }^{1}$ This patient had been seen one year previously when a popliteal cyst had ruptured, resulting, as it usually does, ${ }^{2}$ in an acute inflammatory reaction in the calf tissues. Treatment on that occasion consisted of lavage of the knee joint with recovery of a moderate amount of fine fibrinous debris, followed by injection of $50 \mathrm{mg}$ of hydrocortisone with good results. This intervention does not, however, seem to have had any effect in preventing the development of the present suprapatellar collection.
The clinical picture which we describe here is unique in our experience.

Highfield Hospital,

Droitwich, Worcs WR9 8AF

B L COULTON

A J POPERT

\section{References}

1 Jayson M I V, Dixon A St J. Valvular mechanisms in juxta-articular cysts. Ann Rheum Dis 1970; 29: 415-20.

2 Dixon A St J, Grant C. Acute synovial rupture in rheumatoid arthritis. Clinical and experimental observations. Lancet 1964; i: $742-5$.

\section{Book reviews}

Rheumatological Medicine. By $\mathrm{P}$ A Dieppe, M Doherty, D G Macfarlane, P J Maddison. Pp. 522. £40.00. Churchill Livingstone: Edinburgh. 1985.

Textbooks are just like motor cars; there are minis, middle of the range family cars, and luxury saloons. It is surprising perhaps that rheumatology textbook manufacturers have so neglected the 'family' model but here is one at last and its specification is impressive. The design is excellent-well laid out text, a wealth of summary tables, and a profusion of diagrams which, despite my initial worries, illustrated clinical and radiological points with remarkable clarity.

Under the bonnet is a fairly standard 10 cylinder review of individual conditions. The interior is an unusual but very effective section on the inter-relations of joint diseases with other systems and of systemic diseases with joints. The back seat is split, a selection of disorders of bone and collagen next to a section on soft tissue and traumatic conditions. The boot is capacious, with sections on diagnosis and treatment. This is a practical approach for clinicians and avoids a good deal of repetition.

My only regret was that the predelivery checks were inadequate and there was a large number of irritating faults in spelling and grammar. The worst of these was the e-i transposition, which resulted in the arid new disease osteochondritis dessicans. Also I became obsessed with the identity of the artist whose initials appeared in various calligraphic forms under the diagrams. Who was he? I think we should be told.

There is no doubt though that the whole package will appeal to learners and advanced drivers alike, and every rheumatology department, postgraduate centre library, and general practice should have one, if not a fleet. I think though that it is a bit big for the average MRCP candidate, who would be better served by a mini (e.g., Currey's Essentials of Rheumatology) as they have a lot of other specialties to drive. But this is a 'textbook of the year', and any other makers will be very hard put to come up with anything but a cheap imitation.

Consultant Rheumatologist,

ANDREW BAMJI

Brook General Hospital,

London and Queen Mary's Hospital,

Sidcup.
Clinics in Rheumatic Diseases. Seronegative Spondyloarthropathies. Edited by G Panayi. Pp. 173. f15·00. Saunders: Eastbourne. 1985.

Books in this series are generally valuable sources of reference and high priority reading for practising rheumatologists. This one is no exception. It is a multiauthor product with individual chapters devoted to genetics, reactive arthritis, ankylosing spondylitis, psoriatic arthritis, inflammatory bowel disease, radiology, and management. Most of the authors are well known and have produced well referenced and workmanlike text with an adequate number of black and white illustrations and a total of 747 references give or take some duplication.

Inevitably some contributions are somewhat personalised, such as that on ankylosing spondylitis with 21 of the 126 references cited being written by the author. I particularly enjoyed the chapter on psoriatic arthritis by Rodger Laurent and that on reactive arthritis by Marjatta Leirisalo-Repo and colleagues. Both contain very comprehensive collations of clinical and genetic data and both grasp at least some of the nettles of the major areas of uncertainty and controversy. Similarly, Martin Richter's chapter on management is interesting and contains wide ranging and sensible information which practising clinicians will find helpful, as well as citing 150 references.

Although most authors touch upon some of the current controversies in this rapidly developing area of rheumatology, it is perhaps a pity that a more frontal approach, such as a debate on the klebsiella issue, was not also included. Inevitably different authors clearly differ in their views of these diseases, but there are plenty of facts and also a healthy sprinkling of contentious statements. Several authors also list important facts still in search of explanations and particular areas of uncertainty which are not discussed, and this is a very helpful approach in pin pointing essential elements of hypotheses and areas for further thought and research.

This is not a textbook but a collection of informative reviews. In general, they accurately present the state of the art, but in this age of so many reviews this does not stand out with particular brilliance. However, the text is well written, up to date, and reasonably comprehensive. Rheumatologists in training will certainly benefit from 